ISSN: 2238-8052

\title{
CONSTRUÇõES SOCIAIS E COMPLEXIDADES NA GESTÃO DA PESCA ARTESANAL
}

\author{
SOCIAL CONSTRUCTIONS AND COMPLEXITIES IN THE MANAGEMENT OF ARTISANAL \\ FISHERIES
}

Ivo Raposo Gonçalves CIDREIRA-NETO ${ }^{1}$

Gilberto Gonçalves RODRIGUES ${ }^{2}$

Artigo recebido em 17/10/2018 e aceito em 17/12/2018

Palavras-chave:

Comunidade

Tradicional;

Comunidade

Pesqueira;

Pescadores;

Gerenciamento da

Pesca.

\section{Keywords: \\ Traditional \\ Community; Fishing \\ Community; \\ Fishermen; Fisheries \\ Management.}

\begin{abstract}
R E S U M O
A pesca artesanal é uma atividade amplamente realizada no Brasil, com registros históricos provenientes dos indígenas, que utilizavam os recursos pesqueiros para alimentação. 0 estudo tem como objetivo compreender como são formadas as relações sociais na pesca artesanal e os conhecimentos provenientes dessa atividade, assim como as formas de gestão para garantia da continuidade e sustentabilidade pesqueira. Para isso, o estudo foi construído a partir de pesquisas bibliográficas em periódicos especializados, assim como a legislação pesqueira, utilizando a dialética para construção e análise de dados. A relação do pescador com o ambiente é resultado de complexos fatores, que vão desde a utilização de apetrechos artesanais na captura do pescado, como a percepção do ambiente pesqueiro, chegando até o complexo sentimento do que vem a ser o trabalho, fugindo dos padrões urbano-capitalista. No entendimento da gestão desse setor, a constante mudança no órgão competente acarreta em problemas de reconhecimento da pesca, desvalorizando essa atividade e desestimulando o pescador a continuar com o desenvolvimento dessa atividade tradicional. Dessa forma, tem-se necessidade de uma melhor gestão da pesca, inclusiva e representativa.
\end{abstract}

\begin{abstract}
A B S T R A C T
Artisanal fishing is an activity widely carried out in Brazil, with historical records coming from the natives, who used the fishing resources for feeding. The study aims to understand how social relations are formed in artisanal fishing and the knowledge derived from this activity, as well as the ways of managing the fishing activity. For this, the study was constructed from bibliographical researches in specialized journals, as well as fisheries legislation, using the dialectic for construction and data analysis. The fisherman's relationship with the environment is the result of complex factors, ranging from the use of handcrafted fish catching tools such as the perception of the fishing environment, reaching the complex feeling of what the work is, avoiding urban patterns capitalist. In the understanding of the management of this sector, the constant change in the competent body causes problems of recognition of the fishing, devaluing this activity and discouraging the fisherman to continue with the development of this traditional activity. In this way, there is a need for better, inclusive and representative fisheries management.
\end{abstract}

\footnotetext{
1 Mestrando do Programa de Pós-Graduação em Desenvolvimento e Meio Ambiente da Universidade Federal de Pernambuco (PRODEMA/UFPE). E-mail: ivo.raposo@hotmail.com (Autor correspondente).

2 Professor do Departamento de Zoologia da Universidade Federal de Pernambuco, UFPE. E-mail: gilberto.rodrigues@ufpe.br.
} 


\section{INTRODUÇÃO}

A pesca é uma atividade realizada antes mesmo do período colonial no Brasil, desenvolvida pelas comunidades indígenas que utilizavam variadas espécies de peixes, moluscos e crustáceos na sua alimentação, assim como complexas formas de coleta desses organismos (DIEGUES, 1999). Posteriormente, no período colonial até os atuais dias, a pesca ainda é uma atividade realizada de forma representativa, abrangendo novos grupos sociais como os caiçaras, jangadeiros, açorianos (DIEGUES, 1999), assim como catadores de caranguejos e siris, marisqueiras, sururuzeiras, ostreiras. Dessa forma, a pesca, quanto atividade extrativista, está presente no Brasil durante todo o processo de construção nacional, passando por todos os cenários políticos-culturais (SANTOS et al., 2012), não estando alheio aos processos econômicos.

O entendimento acerca das relações socioambientais da pesca artesanal, bem como dos complexos processos acerca das constantes mudanças do órgão competente do setor pesqueiro, possibilita o planejamento de ações que visem contribuir com a continuidade da atividade através do subsidio para uma gestão integrada e participativa, garantindo representatividade para os pescadores. Partindo desse entendimento, o artigo teve como objetivo compreender como são formadas as relações sociais na pesca artesanal e os conhecimentos provenientes dessa atividade, assim como as formas de gestão para garantia da continuidade e sustentabilidade pesqueira.

As reflexões presentes nesse artigo foram construídas a partir de construções teóricas, provenientes de levantamento bibliográfico (GIL, 2008), durante o ano de 2018, utilizando artigos publicados em periódicos especializados na área, que tratam das diferentes interfaces da pesca artesanal, enfatizando as relações socioambientais dos pescadores. Foi consultado também as legislações competentes ao setor pesqueiro, realizando uma abordagem evolutiva das principais medidas normativas.

Este estudo apresenta caráter qualitativo, construída a partir da abordagem dialética (GIL, 2008). A estrutura do artigo está dividida em dois capítulos, sendo o primeiro abordando sobre o universo da pesca artesanal, discutindo como essa atividade se enquadra como tradicional, bem como do próprio entendimento dos saberes adquiridos pelo pescador, trazendo assim uma relação com a busca das etnociências nessa perspectiva. O segundo capítulo retrata a partir de uma abordagem histórica, as mudanças e divergências entre os setores competentes da gestão pesqueira, o que dá base para o entendimento das próprias mudanças na estrutura da pesca artesanal. 


\section{PESCA ARTESANAL COMO ATIVIDADE TRADICIONAL}

As comunidades tradicionais, bem como os grupos sociais que o compõem, configuram um cenário heterogêneo, por vezes dificultando conceituações que contemplem todos (PEREIRA e DIEGUES, 2010). Essa abrangência que o tema remete é proposital, fugindo do comodismo científico, que os retratam unicamente como sustentáveis e fora dos padrões capitalista (CUNHA e ALMEIDA, 2000), ignorando a própria evolução a qual todas as comunidades estão sujeitas.

Como forma de entendimento as mudanças que vem constantemente ocorrendo, tem-se o conceito proposto por Diegues (2000), que define comunidade tradicional como:

[...] grupos humanos culturalmente diferenciados que historicamente reproduzem seu modo de vida, de forma mais ou menos isolada, com base em modos de cooperação social e formas específicas de relações com a natureza, caracterizados tradicionalmente pelo manejo sustentado do meio ambiente (DIEGUES, 2000, p.22).

Nos anos 2000, quando Diegues publica essa definição, ainda se tinha uma tendência a reconhecer apenas as comunidades isoladas dos centros urbanos, impossibilitando que as demais comunidades fossem contempladas. O termo "mais ou menos isoladas" é o exemplo de que, para ser considerada tradicional, a comunidade não poderia ter influência dos modelos econômicos presentes, o que de certa forma, não condiz com a realidade. Como contraposto, em 2007, é sancionado o Decreto no 6.040, de 7 de fevereiro, institui a Política Nacional de Desenvolvimento Sustentável e Povos Tradicionais, abarcando uma gama de pesquisadores da área para construir um conceito legal, chegando a tal definição de comunidades tradicionais:

[...] grupos culturalmente diferenciados e que se reconhecem como tais, que possuem formas próprias de organização social, que ocupam e usam territórios e recursos naturais como condição para sua reprodução cultural, social, religiosa, ancestral e econômica, utilizando conhecimentos, inovações e práticas gerados e transmitidos pela tradição.

Já se percebe um conceito com amplitude para o reconhecimento de outras populações, como quebradeiras de coco babaçu e pescadores artesanais (SILVA, 2007). Esse reconhecimento possibilita que políticas públicas estejam voltadas para esses povos, assim como assegurar o acesso ao território, que abrange tanto questões físicas, quanto cosmológicas (SILVA, 2007).

Adentrando no contesto da pesca artesanal nacional, essa atividade, segundo Diegues (1983) está enquadrada nos moldes da pequena produção mercantil, juntamente com os pescadoreslavradores. Essa categoria abrange populações que tem como base a realização de uma atividade tradicional, porém não se encontram fora das relações de comércio. Cabe aqui frisar, que se utilizarmos essa categoria para as demais comunidades, outros grupos podem ser enquadrados, como por exemplo as quebradeiras de coco babaçu, agricultores familiares, alguns grupos quilombolas e seringueiros.

CIDREIRA-NETO, I. R. G.; RODRIGUES, G. G. Construções sociais e complexidades na gestão da pesca artesanal. 
No universo da pesca artesanal, como definição, tem-se que são comunidades que apresentam a pesca como principal atividade, contendo ritmos, estratégias de coleta e saberes próprios, apropriados a partir da oralidade e prática. Além da importância cultural, a pesca artesanal é responsável por mais da metade da produção pesqueira do Brasil, sendo o Nordeste a região que mais produz, em seguida tem-se o Norte (SILVA, 2014).

De forma geral, a pesca artesanal é desenvolvida com o auxílio de poucos equipamentos, como pequenas embarcações a remo ou motorizadas, que podem ser construídas pelo próprio pescador, ou adquirida através da compra, e pequenos apetrechos de pesca, como lança, rede de malha (pano de rede), puçá, entre outros. Existe uma variação de nomes acerca os apetrechos utilizados na pesca artesanal, visto que muito deles são confeccionados pelos próprios pescadores, ou pela comunidade local, surgindo modificações para adequar o instrumento a realidade local.

Inicialmente essa atividade era realizada pelos indígenas, que utilizavam a pesca para alimentação. Já as comunidades pesqueiras artesanais, foram formadas a partir da quebra do sistema açucareiro e cafeeiro, fazendo com que os lavradores migrassem exclusivamente para a atividade pesqueira (ADAMS, 2000). A cultura da pesca artesanal, nas diversas comunidades formadas, foi desenvolvida e transmitida através das experiências vividas (RAMIRES, MOLINA e HANAZAKI, 2007), resultando em um amplo conhecimento agregado pelos pescadores acerca da ecologia local (PAZ e BEGOSSI, 1996; SANTOS-FITA e COSTA-NETO, 2007).

0 trabalho torna-se uma categoria complexa na pesca artesanal, visto que por diversas vezes ele se confunde com o sentimento e momentos de lazer. Ramalho (2015) aponta que:

As relações socioculturais e econômicas, em alguns grupos de pescadores artesanais e camponeses, não colocaram como entes antagônicos trabalho e tempo livre. Ao contrário, tais relações celebram aproximações e indissolubilidades entre saber-fazer pesqueiro, lazer e vida, formando e conformando um todo societário (RAMALHO, 2015, p.194).

$\mathrm{O}$ fato de ir para a maré/mar traz um sentimento de lazer, devido a atividade ser realizada em contato com o meio ambiente, o contato com o grupo social, que por vezes são vizinhos e parentes, possibilita a troca de experiências e interação. A ida para a maré sozinho(a) resulta em momentos de reflexão e de autoconhecimento. Dessa forma, o trabalho em si traz uma construção diferenciada do trabalho urbano-capitalista, baseada em hierarquias e sentimentos contrários ao de lazer.

A relação do pescador com a pesca vai além de uma relação homem - trabalho, sendo construída a partir dos núcleos coletivos que vão em conjunto para o mar. Ramalho (2012) relata que o grupo social que realiza a pesca apresenta sentimento de corporação, embebida na ética comunitária e no respeito, deixando em segundo plano o fator econômico para dar lugar ao afetivo, onde mesmo o 
mestre (reconhecido pela comunidade devido a sua experiência) se deixa ouvir os demais, para uma construção coletiva.

A paisagem costeira inclui a presença dos pescadores, que modificam o espaço a partir da sua prática, onde seu ritmo se enquadra com a própria dinâmica ambiental das marés (SILVEIRA et al., 2013). Leff (2002, p.160) comenta que o ambiente é uma categoria sociológica, e não um simples meio com espécies e populações, dessa forma a zona costeira agrega além da sua diversidade biológica a dinâmica humana.

A partir das experiências sociais e ambientais, o pescador artesanal permite se reinventar e se reconhecer como pescador, dialogando com a natureza, formando o seu eu social (RAMALHO, 2011). Dessa forma, a conservação das espécies, bem como dos ecossistemas associados à pesca artesanal, garante a continuidade do "ser pescador", assim como de toda a tradicionalidade envolvida nessa atividade tradicional, da mesma forma que a permanência do pescador, indiretamente, influência na conservação do ambiente pesqueiro.

\subsection{Ser Pescador e o Olhar Das Etnociências}

A classe pesqueira representa complexas relações, contendo particularidades quanto ao modo de vida, assim como do próprio sentimento quanto o "saber e fazer pescador", lapidado e construído a partir das experiências vividas (RAMALHO, 2011). 0 saber e fazer pescador engloba complexas relações, somando o entendimento do ambiente pesqueiro, fatores biológicos e ecológicos, bem como das relações sociais, passiveis a adaptações proporcionadas pelo desenvolvimento da atividade.

O entendimento do que corresponde ao território pesqueiro, também é resultado de diferentes variáveis, como a integração entre o ambiente aquático, compreendendo o local de desenvolvimento da pesca, o meio intermediário, que corresponde aos locais de beneficiamento, e o meio terrestre, com a localização das residências. Nesse contesto, a territorialidade pesqueira abrange inter-relações socioambientais (CARDOSO, 2003), bem como o contexto econômico, voltado para a venda e distribuição do produto pescado. Dessa forma, as comunidades pesqueiras podem ser caracterizadas como um sistema cultural de sociabilidades distintas, contendo as noções de espaço de forma tridimensional, que inclui experiências acumuladas acerca o mar, terra e céu, além da interação de pescadores e diversificação das formas de manejo do pescado (CUNHA, 2003). Os pescadores artesanais que integram ativamente a comunidade, se reconhecem a partir de conceitos históricos, culturais e de identidade (JENTOFT, MC-CAY e WILSON, 1998), que reforçam sua natureza.

As complexidades que envolvem o ser pescador partem do próprio entendimento do corpo, que Ramalho (2011, p.317) pontua claramente que "corpo é o território sobre o qual ele se torna CIDREIRA-NETO, I. R. G.; RODRIGUES, G. G. Construções sociais e complexidades na gestão da pesca artesanal. 
pescador, sendo inescapável aos homens que voltam seu trabalho para o setor pesqueiro". Seguindo nesse raciocínio, o "fazer pescador" está interligado com o fato de "ser pescador", compreendendo questões de território, assim como o complexo K (Kosmo) - C (Corpus) - P (Práxis), que envolve, respectivamente, as crenças o conhecimento e a prática (TOLEDO e BARRERA-BASSOLS, 2008; 2009).

Realizando uma analogia, as complexidades que envolvem o ser pescador, podem ser comparadas com a rede de pesca, que a partir de diversas conexões dos fios a tecem, dando forma a esse apetrecho, como ocorre com o pescador. Os complexos emaranhados do que diz respeito a tradição da pesca artesanal forma então os mestres, que dominam e desenvolvem a atividade pesqueira.

Esse conhecimento é adquirido a partir do envolvimento diário que os pescadores com os rios, manguezais e áreas marinhas, proporcionam conjunto de conhecimentos aprofundados acerca das variáveis ecológicas e ambientais, tais como fluxo migratório, escalas sazonais, recursos faunísticos mais abundantes por região, assim como da biologia dos organismos (MOURÃO e NORDI, 2006). Para os pescadores esse conhecimento é adquirido com a prática e oralidade, possibilitando que eles se reafirmem como experientes na comunidade, por vezes conhecido como "especialista nativos" pelos pesquisadores nas áreas da etnociência (e.g., BARBOSA et al., 2007; SILVA et al., 2015).

A ciência tradicional cartesiana por muito tempo questionou essa forma de conhecimento, tentando enquadrar nas suas construções baseadas no teste de hipótese. Cypriano e Teixeira (2017, p.4), trazem um importante questionamento a respeito da legitimidade absoluta da ciência, assim como dos moldes engessados que servem como protocolos:

A ciência é uma construção humana e uma poderosa instituição social que influencia diretamente a vida de todos nós. Contudo não buscamos estudar e compreender mais a fundo esta organização de forma crítica, sendo as afirmações científicas aceitas como verdades absolutas pela maior parte da população sem grandes questionamentos. Isto é evidenciado pelo poder atual da expressão: 'comprovado cientificamente', que exibe uma grande influência no pensamento e na conduta das pessoas... a conjuntura e a estrutura da própria comunidade científica são muito pouco estudadas e questionadas (CYPRIANO e TEIXEIRA, 2017, p.4).

A etnociência sugue entre a década de 1950 e 1970, sendo construída por bases antropológicas, utilizando os sistemas cognitivos para entender como os atores sociais, de uma determinada cultura, enxergam o mundo (COUTO, 2007). Essa ciência traz como finalidade a valorização do conhecimento humano/tradicional, oposta a rigidez do conhecimento científico, podendo ser chamada de ciência do povo (STRACHULSKI, 2017).

Medeiros e Albuquerque (2012) comentam que essa nova ciência vem embebida de trajes antropológicos, valorizando os comportamentos culturais e suas inter-relações, trazendo como um sistema de conhecimento. A forma como comunidades tradicionais se relaciona com a natureza não é 
passível de ser analisada, em sua maior plenitude, sob uma perspectiva isolada, tornando essa ciência multi-, inter- e transdisciplinar (STRACHULSKI, 2017). O próprio ser pescador envolve complexos fatores, necessitando assim, para o seu entendimento, um olhar interdisciplinar.

A etnociência é uma matriz que acolhe diversas perspectivas, assim como diversas áreas do conhecimento. Diegues (2000) comenta que os etnocientista são uma nova geração de cientistas naturais, atrelando políticas conservacionista atreladas a participação popular. Como frutos dessa ciência, e com objetivo de adequar as pesquisas, surgem alguns seguimentos, como: (i) etnobiologia; (ii) etnoecologia; (iii) etnozoologia (DIEGUES, 2000; ROUÉ, 2000).

Como forma de conceituar algumas das ramificações da etnociência, bem como citar alguns trabalhos para um melhor entendimento, segue a tabela 1.

Tabela 1. Conceito e literatura complementar dos ramos da etnociência.

\begin{tabular}{|c|c|c|}
\hline Etnociência & Conceito & Literatura \\
\hline Etnobiologia & $\begin{array}{l}\text { Busca entender as interações entre humanos, não- } \\
\text { humanos para e com o meio ambiente, ressaltando } \\
\text { as relações culturais e biológicas (ALBUQUERQUE } \\
\text { e ALVES, 2014) }\end{array}$ & $\begin{array}{ll}\text { - } & \text { ALBUQUERQUE et al., } \\
2013 & \\
\text { - } & \text { FRAGOSO et al., } 2018\end{array}$ \\
\hline Etnoecologia & $\begin{array}{l}\text { Busca entender as relações entre o conjunto de } \\
\text { conhecimentos, crenças, sentimentos e } \\
\text { comportamentos com os elementos naturais } \\
\text { (MARQUES, 2001) }\end{array}$ & $\begin{array}{l}\text { - } \text { BARRERA-BASSOLS e } \\
\text { TOLEDO, } 2005 \\
\text { PRADO e MURRIETA, } \\
2015 \\
\text { - TOLEDO e BARRERA- } \\
\text { BASSOLS, } 2009\end{array}$ \\
\hline Etnozoologia & $\begin{array}{l}\text { Busca entender as relações entre humanos e não- } \\
\text { humanos, a partir de aspectos históricos, } \\
\text { econômicos, sociológicos, antropológicos e } \\
\text { ambientais (ALVES e SOUTO, 2015) }\end{array}$ & $\begin{array}{ll}\text { - } & \text { ALVES, 2012 } \\
\text { - } & \text { BENÍTEZ, 2011 } \\
\text { - } & \text { SEIXAS e BEGOSSI, } 2001\end{array}$ \\
\hline
\end{tabular}

Fonte: Autores, 2018.

A pesca artesanal, bem como os pescadores que compõem esse grupo, são investigados pela etnociência, envolvendo diversas questões, como taxonomia, distribuição dos grupos de peixes, técnicas de pesca, conhecimento ecológico local, entre outros. Essa abordagem vai depender do 
objetivo da pesquisa, assim como dos procedimentos metodológicos utilizados, bem como o seu público alvo da pesquisa, que no caso da pesca artesanal podem ser os pescadores de peixes (tainha, carapeba, bagre, sauna, xaréu, camurim, entre outros), de moluscos (marisco, sururu, ostra, unha de velho e taioba) e de crustáceos (guaiamum, caranguejo, aratu e siri). Cada arte pesqueira vai envolver diferentes conhecimentos, construídos a partir da realidade a qual a atividade proporciona.

Cabe ressaltar que a pesca de moluscos, conhecida popularmente como mariscagem, traz uma representatividade feminina na pesca artesanal, devido a sua representatividade, reafirmando seu trabalho quanto pescadoras. Conhecido como o trabalho na maré, regrado por diversos fatores ambientais atuantes como a mudança na salinidade, pH e temperatura, os pescadores e pescadoras dessa atividade apresentam relevante conhecimento ambiental, assim como da própria dinâmica do organismo catado, sendo comumente investigado por etnocientistas (NISHIDA, NORDI e ALVES, 2004; SOUTO e MARTINS, 2009).

A forma de coleta pode variar dependendo do habitat, nos bivalves que vivem soterrados nas zonas de praias e manguezais, a catação ocorre de forma manual e/ou com o auxílio de instrumentos, como o puçá, jereré e gadanho, que maximizam a captura (e.g., DIAS, ROSA e DAMASCENO, 2007). Já os que vivem aderido a um substrato, é utilizada uma faca (ou similar) para auxiliar na retirada. A presença de uma embarcação (baitera/caico) amplia as zonas de catação, facilitando a exploração em locais mais desertos ou pouco explorados. Bezerril (2012) traz uma importante reflexão sobre a mariscagem:

Para aqueles que não estão envolvidos com a pesca, mariscar pode parecer, à primeira vista, uma prática sem maiores elaborações, mas sob um olhar atento, a atividade se constitui como um campo de complexas relações, saberes, significados e interesses que vêm sendo construídos ao longo da história e são afirmados na memória de um grupo de mulheres (BEZERRIL, 2012, p.6).

As (des)construções proporcionadas pela atividade de catação traz aspectos perdidos nas relações de trabalho atual, como uma forma diferenciada de perceber o meio ambiente, assim como da própria forma de se relacionar no meio social. Caetano (2015) traz uma reflexão perspicaz:

$\mathrm{Na}$ mariscagem, os traços simbólicos apreendidos e ensinados na ancestralidade, através da convivência assídua com a biodiversidade marinha, marcam o modo de a marisqueira ver o mundo e de se relacionar com a com a natureza. Assim, quando o espaço natural se torna sociabilizado por esses indivíduos, ganha tons e formas diversificadas, transformando o lugar habitado em objeto de manifestação das subjetividades, da construção social de significados e da assimilação de práticas, princípios e valores que passam a constituir o ethos da comunidade (CAETANO, 2015, p.206).

As relações sociais estão interligadas as ambientais, demonstrado que as formas de vida/trabalho mais artesanais são construídas a partir do cruzamento de diversas esferas, descaracterizando quando separadas. 


\section{OS DESENCONTROS NA GESTÃO DA PESCA}

A partir de uma abordagem histórica, o primeiro grande marco na gestão da pesca foi a criação da Superintendência do Desenvolvimento da Pesca (SUDEPE), instituída pela Lei Delegada no 10, de outubro de 1962. Anterior a SUDEPE, o gerenciamento da pesca estava relacionado ao Ministério da Agricultura, criando o Código da Pesca e o Fundo de Crédito da Pesca, subsidiando o desenvolvimento produtivo do setor. Anteriormente, em 1961, teve a criação do Conselho de Desenvolvimento da Pesca (CODEPE), aprovado pelo Decreto no 50.872, de 28 de junho de 1961, sendo de fundamental importância para a criação da SUDEPE no ano seguinte.

A SUDEPE incentivou, através do financiamento, o desenvolvimento e modernização das práticas e técnicas pesqueiras, trazendo empreendimentos da pesca industrial para o Brasil, ocasionando na exploração exacerbada de algumas espécies (SILVA, 1998). Esse período é marcado pela exploração desenfreada dos recursos pesqueiros, fortalecendo a indústria que promovia a pesca modernizada, e excluindo a importância do pescador artesanal. 0 padrão para o momento era industrialização, resultado da Revolução Industrial, tanto para o setor pesqueiro, quanto para as demais áreas.

Cardoso (2009) demonstra que essa industrialização da pesca resultou no aumento da produção pesqueira do Brasil, apresentando forte influência na destruição de habitats e ecossistemas importantes para a manutenção do pescado, assim como na redução de espécies. A SUDEPE acompanhou os processos políticos do Brasil, sendo criada durante a democracia, passando pelo golpe civil-militar de 1964, no qual os militares que indicavam o superintendente, apresentando como principais feitos o Decreto no 221, de 28 de fevereiro de 1967 (dispõe sobre os estímulos a pesca) (GOULARTI-FILHO, 2017). A década de 1970 continua com o mesmo impulsionamento na industrialização da pesca, marcado pelo constante desvio de verbas do Fundo de Investimentos Setoriais (FISET), iniciando o declive da SUDEPE.

Na década de 1980, a SEDEPE passa por incertezas nas questões de gerência, passando por administrações curtas devido a questões de interesse político. Em 1989, através da Lei no 7.735, de 22 de fevereiro, tem-se a extinção da SUDEPE, assim como da Secretaria Especial do Meio Ambiente (SEMA), criando então o Instituto Brasileiro do Meio Ambiente e dos Recursos Naturais Renováveis (IBAMA). O IBAMA sugue no período de crise financeira, privatizações e cortes de recursos federais. Goularti-Filho (2017) ressalta um importante comentário, a SUDEPE era um órgão que fomentava ações pesqueiras mais do que fiscalizava, já o IBAMA vem como o objetivo maior de fiscalizar com ações punitivas do que fomentar. Dessa forma, ressaltando que "A SUDEPE tornou-se um estorvo para o Estado, e sua ausência um problema para a pesca brasileira. O Ibama consolidou-se como uma conquista para a sociedade civil" (p.405).

CIDREIRA-NETO, I. R. G.; RODRIGUES, G. G. Construções sociais e complexidades na gestão da pesca artesanal. 
A medida realizada pelo IBAMA para atender as questões pesqueiras foi, em 1995, através do Decreto no 1.697, criar o Grupo Executivo do Setor Pesqueiro (GESPE), com o objetivo de subsidiar a Política Nacional da Pesca e Agricultura, assim como os tramites de gestão. A GESPE vem como medida de representar as demandas do setor pesqueiro (DIAS-NETO, 2010).

Paralelamente, no Ministério da Agricultura, Pecuária e Abastecimento (MAPA), tem a criação do Departamento de Pesca e Aquicultura (DPA), instituído através do Decreto no 2.681, no ano de 1998. 0 DPA surge com a proposta de subsidiar ações no desenvolvimento da pesca e supervisionar a produção pesqueira.

Dois órgãos criados em pequena diferença de tempo, responsáveis pela gestão do setor pesqueiro, tiveram sobreposição das atividades competentes, ocasionando conflitos de interesse (DIAS-NETO, 2003). Nesse momento, a pesca começa a passar por problemas, bem como tensão entre os órgãos gestores, no caso o IBAMA e o MAPA (GOULARTI-FILHO, 2017). A GESPE tenta seguir mais para o contexto da criação e implementação de normativas junto a Câmara de Política dos Recursos Naturais, enquanto que o foco do DPA é a busca pelo incentivo para o desenvolvimento da pesca e aquicultura, assim como questões voltadas para a gestão pesqueira.

Até o momento, nenhum dos órgãos competentes atuou de forma direcionada para o pescador artesanal, sendo este excluídos das ações governamentais, vivendo a margem do setor pesqueiro, excluídos de políticas públicas, contribuindo para a desigualdade da pesca (AZEVEDO e PIERRI, 2014). Esse cenário segue até o ano de 2003, que a partir do primeiro mandato do governo de Luís Inácio Lula da Silva, tem-se a criação da Secretaria Especial de Aquicultura e Pesca (SEAP), como órgão de assessoramento da presidência da República nas diretrizes que cabem a pesca e aquicultura, herdando as competências do MAPA/DPA. Dessa forma, a SEAP e o IBAMA acabam possuindo a mesma competência em relação ao setor pesqueiro, ocasionando conflitos de interesse entre dois órgãos federais, resultando em dificuldades nas tomadas de decisão (PEREZ e PEZZUTO, 2006). A SEAP apresentou como medida estratégica a liberação de incentivos para a pesca nacional, no que diz respeito ao apoio em crédito para o desenvolvimento da atividade, sendo a mesma estratégia adotada pela SUDEPE (DIAS-NETO, 2010).

Várias medidas foram tomadas pelos membros da SEAP para que a secretaria fosse transformada em ministério, como o atendimento das demandas do setor pesqueiro, mesmo que estas se tornassem prejudiciais ao mantimento das espécies pescadas (DIAS-NETO, 2010). Em 2008, através da Medida Provisória no 437, de 29 de julho, foi criado o Ministério da Pesca e Aquicultura (MPA), sendo institucionalizada através da Lei no 11.958, de 26 de junho de 2009. 
O MPA contribuiu fortemente para a industrialização da pesca, frequentemente negligenciando os pescadores artesanais, visto que o foco era a modernização e ocupação/utilização das áreas pesqueiras (RAMALHO, 2014). 0 autor ainda traz que esse momento de transição e incentivo as práticas capitalistas podem ser chamadas de Revolução Azul, fazendo alusão a Revolução Verde, complementando que:

As águas passaram a ser vistas como áreas abundantes para a implantação de parques aquícolas - desde que se privatize e se ocultem os usos comuns tradicionais desses recursos naturais pelas comunidades locais - e os pescadores sujeitos a serem convertidos em aquicultores e/ou assalariados do setor como anunciam os dois programas federais (Mais Pesca e Aquicultura e Plano Safra da Pesca e Aquicultura 2012 a 2014) em busca do moderno (RAMALHO, 2014, p.55).

O MPA foi extinto em 2015 pela Medida Provisória no 696, de 2 de outubro, sendo firmada através da Lei no 13.266, de 5 de abril de 2016, trazendo que “Cabe ao Ministério da Agricultura, Pecuária e Abastecimento e ao Ministério do Meio Ambiente, em conjunto e sob a coordenação do primeiro, nos aspectos relacionados ao uso sustentável dos recursos pesqueiros". Dessa forma, o gerenciamento da pesca no Brasil retorna ao MAPA como órgão gestor.

O Decreto no 8701, de 31 de março de 2016, tem-se a criação da Secretaria de Aquicultura e Pesca (SAP), como órgão ligado ao MAPA. A SAP está ligada ao MAPA, mas pouco tempo depois, através do Decreto no 9.004, de março de 2017, a secretaria ficou sob vigência do Ministério da Indústria, Comércio Exterior e Serviços (MICES). Este decreto é regulamentado pelo Decreto no 9.260, de 29 de dezembro de 2017.

A gestão da pesca no Brasil ocorreu de forma desordenada, principalmente a partir do fim da MPA, visto que a constante mudança dos órgãos competentes enfraquece as ações gestoras. Boa parte do processo de construção e reagrupação da gestão da pesca, valoriza a produção em grande escala, excluindo de suas ações os pescadores de pequena escala, como os que desenvolvem a pesca artesanal e/ou tradicional. Como resultado desse crescimento desordenado, Rufino (2016) destaca que a atual situação crítica dos estoques pesqueiros provém da própria crise na gestão, assim como nos interesses implícitos em cada modelo de gestão.

Cabe ressaltar que, a partir do ano 2000, teve-se a criação do Sistema Nacional de Unidades de Conservação (SNUC), instituído pela Lei no 9.985, no caso, durante a vigência de vários órgãos competentes da gestão pesqueira. As unidades de conservação por vezes se enquadram na questão de garantir a perpetuação da pesca artesanal, principalmente nas que contemplam os ecossistemas marinho e manguezal. Porém, não houve integração com a gestão pesqueira, sendo marcado por desencontros e tensão quanto ao uso do território e perpetuação da atividade. 
O SNUC determina dois tipos de UC, as de Proteção Integral (PI) "permitido apenas o uso indireto dos recursos naturais; ou seja, aquele que não envolve consumo, coleta ou danos aos recursos naturais" e Uso Sustentável (US) "são áreas que visam conciliar a conservação da natureza com o uso sustentável dos recursos naturais". Dentre essas duas categorias, existem subdivisões que permitem um melhor enquadramento das necessidades de conservação da área, sendo:

- Proteção Integral: Estação Ecológica, Reserva Biológica, Parque, Monumento Natural e Refúgio de Vida Silvestre.

- Uso Sustentável: Área de Relevante Interesse Ecológico, Floresta Nacional, Reserva de Fauna, Reserva de Desenvolvimento Sustentável, Reserva Extrativista, Área de Proteção e Reserva Particular do Patrimônio Natural.

A ânsia em combater a perda da diversidade biológica, frisando aqui o caso das unidades de conservação, acabam, por vezes, atropelando questões importantes, como entendimento do contexto socioambiental do local, carência no quisto de gestão, bem como conselho gestor. Os conflitos gerados são outro ponto de relevante importância, sendo necessário a adequação de novos modelos institucionais e estruturais, adequando a realidade, garantindo uma gestão integrada, participativa e com representatividade das populações tradicionais locais (VIVACQUA e VIEIRA, 2006). Os povos tradicionais, por vezes, são marginalizados e excluídos do contexto das unidades de conservação (CIDREIRA-NETO e RODRIGUES, 2017), atingindo principalmente pescadores artesanais (e.g., JOVENTINO, JOHNSSON e LIANZA, 2013).

Quando parte da perspectiva da categoria de proteção integral, os conflitos são em relação ao uso do território, não existindo diálogos entre os setores de gestão da pesca e os conselhos das unidades de conservação. No caso das de uso sustentável, o diálogo, mesmo que minimamente, ainda acontece, principalmente quando a gestão é deliberativa. Seixas e Kalikoski (2009), descrevem diversas formas de gestão participativa no setor pesqueiro, mas frisando que essa deveria ser uma prática realizada em nível nacional, onde os atores da pesca se sentissem representados.

O impasses e conflitos na gestão da pesca deixam o pescador artesanal com sentimento de exclusão, não se sentindo representados, principalmente com as constantes mudanças quanto ao órgão gestor. Como buscar ajuda dos órgãos gestores, se nem os pescadores sabem ao certo qual é o ministério responsável? Fora que por vezes a atuação quanto fiscalização só é realizada com o pescador, é não com os grandes empreendimentos de pesca, como no caso da carcinicultura, que influência diretamente na qualidade ambiental do local, aumentando a descredibilidade na gestão pesqueira. 
Ainda sobre essa questão, cabe ressaltar a atual descredibilidade que circula os órgãos ambientais, bem como das ações governamentais que apresentam como finalidade a desqualificação dos movimentos sociais, frisando aqui o caso das comunidades de pescadores.

\section{CONSIDERAÇÕES FINAIS}

A pesca artesanal agrega diversas singularidades e especificidades, correlacionadas com a realidade local, no quesito de relações sociais e condições ambientais. 0 entendimento da pesca é resultado de complexas relações, que partem do entendimento do que é o pescador, bem como do território utilizado, assim como das condições biológicas e ecológicas provenientes dos recursos pesqueiros. A complexidade cognitiva do ser pescador é algo que traz influências do meio social e ambiental, sendo necessário o seu entendimento para construção efetiva do que vem a ser a pesca artesanal.

A questão da gestão é algo que está intimamente ligada a pesca, visto que a constante mudança no órgão gestor, por vezes, confundem e desorganizam o movimento pesqueiro, deixando os pescadores sem saber a quem reivindicar direitos, como a própria carteira de identificação da pesca. Partindo desse ponto de vista, tem-se a necessidade de um retorno do Ministério da Pesca, como órgão central para a sua gestão, assim como o incentivo para a efetivação das colônias de pesca/pescadores, visto que estes conseguem suprir as demandas internas, e reivindicar ações a grande grupo.

A gestão necessita ter pelo menos um representante pescador, pois como conhecer os problemas enfrentados diariamente na pesca se o gestor nunca entrou em um estuário? Além de garantir representatividade, essa estratégia serve como estimulo para que os pescadores se reconheçam quanto pescadores, contribuindo para a valorização da atividade, bem como a sua perpetuação.

\section{AGRADECIMENTOS}

Agradecemos ao Fundo de Amparo à Ciência e Tecnologia do Estado de Pernambuco (FACEPE) pela bolsa de estudos (IBPG - 1179-9.25/16), bem como a todas as comunidades pesqueiras, principalmente as situadas no Estado da Paraíba e Pernambuco. Agradecemos também ao Programa de Pós-Graduação em Desenvolvimento e Meio Ambiente (PRODEMA - UFPE), assim como ao Laboratório de Avaliação, Recuperação e Restauração de Ecossistemas Aquáticos (ARRE-Água UFPE). 


\section{REFERÊNCIAS}

ADAMS, C. As populações caiçaras e o mito do bom selvagem: a necessidade de uma nova abordagem interdisciplinar. Revista de Antropologia, v.43, n.1, p.145-182, 2000.

ALBUQUERQUE, U. P.; ALVES, A. G. C. O que é etnobiologia. In. ALBUQUERQUE, U. P. (org.). Introdução a etnobiologia. Recife: NUPEEA, 2014.

ALBUQUERQUE, U. P.; SILVA, J. S.; CAMPOS, J. L. A.; SOUSA, R. S.; SILVA, T. C.; ALVES, R. R. N. The current status of ethnobiological research in Latin America: gaps and perspectives. Journal of Ethnobiology and Ethnomedicine, v.9, n.72, 2013.

ALVES, R. R. N. Relationships between fauna and people and role of ethozoology in animal conservation. Ethnobiology and Conservation, v.1, n.2, 2012.

ALVES, R. R. N.; SOUTO, W. M. S. Ethozoology: a brief introduction. Ethnobiology and Conservation, v.4, n.1, 2015.

AZEVEDO, N.T.; PIERRI, N. A política pesqueira no Brasil (2003-2011): a escolha pelo crescimento produtivo e o lugar da pesca artesanal. Revista de Desenvolvimento e Meio Ambiente, v.32, p.61-80, 2014.

BARBOSA, A.R.; NISHIDA, A.K.; COSTA, E.S.; CAZÉ, A.L.M. Abordagem etnoherpetológica de São José da Mata - Paraíba - Brasil. Revista de Biologia e Ciência da Terra, v.7, n.2, 2007.

BARRERA-BASSOLS, N.; TOLEDO, V. M. Ethnoecology of the Yucatec Maya: symbolism, knowledge and management of natural resources. Journal of Latin American Geography, v.4, n.1, 2005.

BENÍTEZ, G. Animals used for medicinal and magico-religious purposes in western Granada Province, Andalusia (Spain). Journal of Ethonopharmacology, v.137, p.1113-1123, 2011.

BEZERRIL, G. Trabalho no mangue: os saberes e a busca por valorização das marisqueiras de Fortim - Ceará. Cadernos do LEME, v.4, n.1, p.5-33, 2012.

CAETANO, H. S. Da ocupação do território: práticas e interações entre marisqueiras no ambiente pesqueiro. Revista de Gestão e Sustentabilidade Ambiental, v.3, n.2, p.204-222, 2015.

CARDOSO, E. S. Da apropriação da natureza à construção de territórios pesqueiros. GEOUSP Espaço e Tempo, n.14, p.119-125, 2003.

CARDOSO, E.S. Trabalho e pesca: apontamentos para a investigação. Revista Pegada, v.10, n.2, 2009.

CIDREIRA-NETO, I. R. G.; RODRIGUES, G. G. Relação homem-natureza e os limites para o desenvolvimento sustentável. Revista de Movimentos Sociais e Dinâmicas Espaciais, v.6, n.2, p.142-156, 2017.
COUTO, H. H. Ecolinguistica: estudo das relações entre língua e meio ambiente. Brasília: Thesaurus, 2007.

CUNHA, M. C.; ALMEIDA, M. W. B. Indigenous people, traditional people, and conservation. In the Amazon. Daedalus, v. 129, n. 2, p. 315-338, 2000.

CUNHA, L. H. O. Saberes patrimoniais pesqueiros. Revista de Desenvolvimento e Meio Ambiente, n.7, p.69-76, 2003.

CYPRIANO, R. J.; TEIXEIRA, R. D. B. L. Etnociência da ciência: a busca por simetria na pesquisa científica. Revista Internacional Interdisciplinar, v.14, n.3, p.01-13, 2017.

DIAS, T. L. P.; ROSA, R. S.; DAMASCENO, L. C. P. Aspectos socioeconômicos, percepção ambiental e perspectivas das mulheres marisqueiras da Reserva de Desenvolvimento Sustentável Ponta do Tubarão (Rio Grande do Norte, Brasil). Gaia Scientia, v.1, n.1, p.25-35, 2007.

DIAS-NETO, J. Pesca no Brasil e seus aspectos institucionais - um registro para o futuro. Revista CEPSU - Biodiversidade e Conservação Marinha, v.1, n.1, p.66-80, 2010.

DIEGUES, A. C. S. Pescadores, Camponeses e Trabalhadores do Mar. São Paulo: Ática, 1983.

DIEGUES, A. C. S. A sócio-antropologia das comunidades de pescadores marítimos no Brasil. Etnográfica, 1999.

DIEGUES, A. C. S. Etnoconservação da natureza: enfoques alternativos. In. DIEGUES, A. C. (org.). Etnoconservação: novos rumos para a proteção da natureza nos trópicos. São Paulo: HUCITEC e NUPAUB, 2000.

FRAGOSO, M. L. B.; BARBOSA-NETO, M. V.; CIDREIRA-NETO, I. R. G.; ROSRIGUES, G. G. Use of animals for communities os small farmers in the Refúgio de Vida Silvestre Matas do Sistema Gurjaú Northeast os Brazil. Revista Brasileira de Geografia Física, v.11, n.2, p.477-489, 2018.

GIL, A. C. Métodos e técnicas de pesquisa social. Editora Atlas: 2008.

GOULARTI-FILHO, A. Da Sudepe à criação da Secretaria Especial de Aquicultura e Pesca: as políticas públicas voltadas às atividades pesqueiras no Brasil. Planejamento e Políticas Públicas, n.49, p.385-412, 2017.

JENTOFT, S.; MC-CAY, B. J.; WILSON, D. C. Social theory and fisheries co-management. Marine Policy, v.22, n.4-5, p.423-436, 1998.

JOVENTINO, F.K.P.; JOHNSSON, R.M.F.; LIANZA, S. Pesca artesanal na Baía de Ilha Grande, no Rio de Janeiro: conflitos com unidades de conservação e novas possibilidades de gestão. Política $e$ Sociedade, v.12, n.23, p.159-182, 2013. 
LEFF, E. Epistemologia Ambiental. Tradução Sandra Valenzuela, 2 ${ }^{\underline{a}}$ ed. São Paulo: 2002.

MARQUES, J. G. W. Pescando pescadores: ciência e etnociência em uma perspectiva ecológica. São Paulo: NUPAUB / Fundação Ford, 2001.

MEDEIROS, M. F. T.; ALBUQUERQUE, U. P. The pharmacy of the Benedictine monks: The use of medicinal plants in Northeast Brazil during the nineteenth century (1823-1829). Journal os Ethnopharmacology, v.139, p.280-286, 2012.

MOURÃO, J.S.; NORDI, N. Pescadores, peixes, espaço e tempo: uma abordagem etnoecológica. Interciência, v.31, n.5, p.358-363, 2006.

NISHIDA, A. K.; NORDI, N.; ALVES, R. R. N. Abordagem etnoecológica da coleta de moluscos no litoral paraibano. Tropical Oceanography, v.32, n.1, p.53-68, 2004.

PAZ, V. A.; BEGOSSI, A. Ethnoichthyology of galviboa fishermen of sepetiba bay, Brazil. Journal of Ethnobiology, v.16, n.2, p.157-168, 1996.

PEREIRA, B. E.; DIEGUES, A. C. Conhecimento de populações tradicionais como possibilidade de conservação da natureza: uma reflexão sobre a perspectiva da etnoconservação. Revista de Desenvolvimento e Meio Ambiente, n.22, p.37-50, 2010.

PEREZ, J. A. A.; PEZZUTO, P. R. A pesca de arrasto de Talude do Sudeste e Sul do Brasil: tendências da frota nacional entre 2001 e 2003. Boletim do Instituto de Pesca, v.32, n.2, p.127-150, 2006.

PRADO, H. M.; MURRIETA, R. S. S. A etnoecologia em perspectiva: origens, interfaces e correntes atuais de um campo em ascensão. Ambiente e Sociedade, v.18, n.4, p.139-160, 2015.

RAMALHO, C.W. N. O sentir dos sentidos dos pescadores artesanais. Revista de Antropologia, v.54, n.1, p.315-352, 2011.

RAMALHO, C. W. N. Sentimento de corporação, cultura do trabalho e conhecimento patrimonial pesqueiro: expressões socioculturais da pesca artesanal. Revista de Ciências Sociais, v,43, n.1, p.827, 2012.

RAMALHO, C. W. N. Estado, Pescadores e Desenvolvimento Nacional: da reserva naval à aquícola. RURIS - Revista do Centro de Estudos Rurais, v. 8, n.1, p.31-62, 2014.

RAMALHO, C. W. N. A desnecessidade do trabalho entre pescadores artesanais. Sociologias, v.17, n.38, p.192-220, 2015.

RAMIRES, M.; MOLINA, S. M. G.; HANAZAKI, N. Etnoecologia caiçara: o conhecimento dos pescadores artesanais sobre aspectos ecológicos da pesca. Revista Biotemas, v.20, n.1, p.101-113, 2007.

ROUÉ, M. Novas perspectivas em etnoecologia: "saberes tradicionais" e gestão dos recursos naturais. In. DIEGUES, A. C. (org.).
Etnoconservação: novos rumos para a proteção da natureza nos trópicos. São Paulo: HUCITEC e NUPAUB, 2000.

RUFINO, M. L. A gestão dos recursos pesqueiros do Brasil. In. ARAÚJO, Marcos Antônio Reis. Repesando a gestão ambiental no Brasil: uma contribuição ao debate de reconstrução nacional. Belo Horizonte: Kindle, 2016.

SANTOS, M.P.N.; SAIXAS, S.; AGGLO, R.B.M.; HANAZAKI, N.; COSTA, M.; SCHIAVETTI, A.; DIAS, J.A.; AZEITEIRO, U.M. A pesca enquanto atividade humana: pesca artesanal e sustentabilidade. Revista de Gestão Costeira Integrada, v.12, n.4, p.405-427, 2012.

SANTOS-FITA, D.; COSTA-NETO, E. M. As interações entre os seres humanos $\mathrm{e}$ os animais: a contribuição da etnozoologia. Revista Biotemas, v.20, n.4, p.99-110, 2007.

SEIXAS, C. S.; BEGOSSI, A. Ethnozoology of fishing communities from Ilha Grande (Atlantic Forest Coast, Brazil). Journal of Ehtnobiology, v.21, n.1, p.107-135, 2001.

SEIXAS, C. S.; KALIKOSKI, D. C. Gestão participativa da pesca no Brasil: levantamento das iniciativas e documentação dos processos. Revista de Desenvolvimento e Meio Ambiente, n.20, p.119-139, 2009.

SILVA, L. G. S. História e Meio Ambiente: a pequena pesca marítima no Brasil. Revista de Sociologia e Política, v.10, n.12, p.219-231, 1998.

SILVA, M. O. Saindo da Invisibilidade - a política nacional de povos e comunidades tradicionais. Inclusão Social, v.2, n.2, p.7-9, 2007.

SILVA, A. P. Pesca artesanal brasileira: aspectos conceituais, históricos, institucionais e prospectivos. Palmas: Embrapa Pesca e Aquicultura, 2014.

SILVA, C. G.; MARINHO, M. G. V.; LUCEMA, M. F. A.; COSTA, J. G. M. Levantamento etnobotânico de plantas medicinais em área de Caatinga na comunidade do Sítio Nazaré, município de Milagres, Ceará, Brasil. Revista Brasileira de Plantas Medicinais, v.17, n.1, p.133-142, 2015.

SILVEIRA, P. C. B.; MESQUITA, B.; MELO, L.; OLIVEIRA-FILHO, I. Estuário, paisagem-fluxo de pescadores artesanais. Iluminuras, v.14, n.34, p.304-323, 2013.

SOUTO, F. J. B.; MARTINS, V. S. Conhecimentos etnoecológicos na mariscagem de moluscos bivalves no manguezal do distrito de Acupe, Santo Amaro - BA. Biotemas, v.22, n.4, p.207-2018, 2009.

STRACHULSKI, J. Etnociências e teoria da complexidade: aproximando referências para compreender os conhecimentos tradicionais. Revista Contribuciones a las Ciencias Sociales, 2017. 
TOLEDO, V; BARRERA-BASSOLS, N. La memoria biocultural: la importância ecológica de las sabidurías tradicionales. Icaria editorial, 2008.

TOLEDO, V.; BARRERA-BASSOLS, N. A etnoecologia: uma ciência pós-normal que estuda as sabedorias tradicionais. Revista de Desenvolvimento e Meio Ambiente, n.20, p.31-45, 2009.

VIVACQUA, M.; VIEIRA, P. F. Conflitos socioambientais em unidades de conservação. Política e Sociedade, n.7, 2006. 